\title{
RESPOSTA DO GERGELIM À ADUBAÇÃO COM ESTERCO BOVINO E DOSES DE FÓSFORO NO SUL DE TOCANTINS
}

\author{
Response from sesame to fertilization with cattle manure and doses of phosphorus in the south of Tocantins
}

\author{
Jefferson Santana da Silva Carneiro ${ }^{1 *}$; Paulo Sérgio Santos Silva²; Gilson Araújo de Freitas³; Antonio Clementino dos \\ Santos ${ }^{4}$; Rubens Ribeiro da Silva ${ }^{5}$

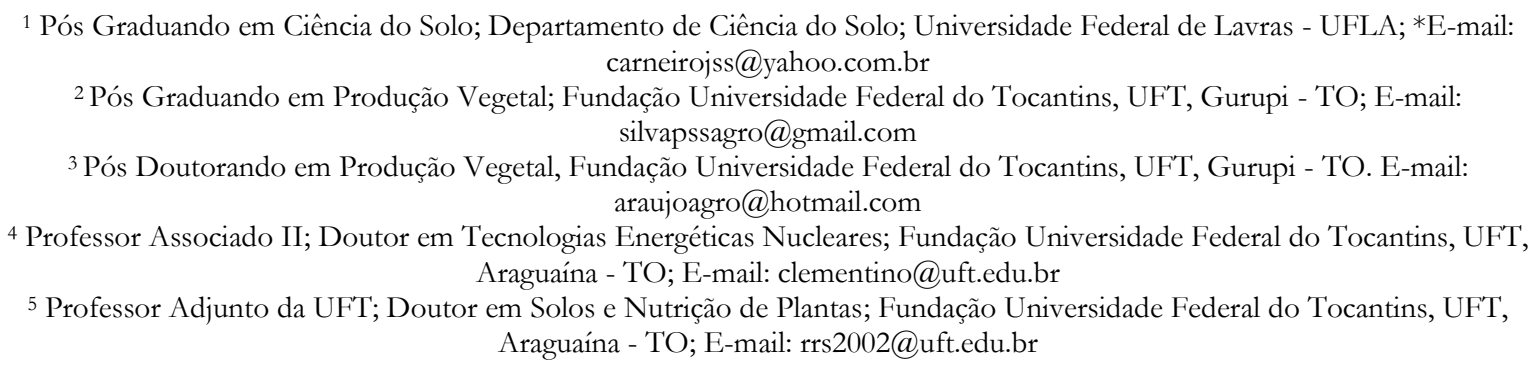

Artigo enviado em 18/09/2016, aceito em 23/11/2016 e publicado em 20/12/2016.

\begin{abstract}
Resumo - A utilização de esterco bovino e outros resíduos orgânicos é uma boa alternativa para a melhoria das condições físicas e químicas dos solos cultivados. O presente trabalho objetivou avaliar a efeito de diferentes níveis de adubação orgânica e fosfatada no cultivo de gergelim cv. Trhébua no Sul do Tocantins. O trabalho foi realizado seguindo um delineamento em blocos casualizados em esquema fatorial $4 \times 5$, o primeiro correspondendo às doses da adubação fosfatada $\left(0,40,80\right.$ e $120 \mathrm{~kg}$ de $\left.\mathrm{P}_{2} \mathrm{O}_{5} \mathrm{ha}^{-1}\right)$ e o segundo fator às doses de esterco bovino curtido $(0,16,7$, 33,3, 50 e 66,7 Mg ha-1). Foi avaliada a altura de plantas, altura de inserção da primeira cápsula, quantidade de cápsulas por planta, quantidade de sementes por cápsula, peso de mil sementes e produtividade por planta. A adubação orgânica com o esterco bovino e a adubação fosfatada influenciou de forma significativa para as variáveis estudadas, tendo apresentado na maioria delas resposta linear. A adubação orgânica com esterco apresentou efeito semelhante ou superior à adubação química fosfatada.
\end{abstract}

Palavras-Chave - Sesamum indicum. Agricultura familiar. Resíduos orgânicos. Cultivo orgânico. Cerrado.

\begin{abstract}
The use of cattle manure and other organic wastes is a good alternative for improving the physical and chemical conditions of cultivated soils. The present work aimed to evaluate the effect of different levels of organic and phosphated fertilization on the crop of sesame cv. Trhébua in the South of Tocantins. The work was carried out in a randomized complete block design in a 4 x 5 factorial scheme, the first one corresponding to the doses of phosphate fertilization $\left(0,40,80\right.$ and $120 \mathrm{~kg}$ of $\left.\mathrm{P}_{2} \mathrm{O}_{5} \mathrm{ha}^{-1}\right)$ and the second factor to the doses of cattle manure $(0,16.7,33.3,50$ and $\left.66.7 \mathrm{Mg} \mathrm{ha}^{-1}\right)$. The height of plants, height of insertion of the first capsule, amount of capsules per plant, amount of seeds per capsule, weight of one thousand seeds and productivity per plant were evaluated. Organic fertilization with cattle manure and phosphated fertilization had a significant influence on the studied variables, and presented a linear response in most of them. The organic fertilization with cattle manure presented similar or superior effect to the chemical phosphated fertilization.
\end{abstract}

Keywords - Sesamum indicum. Family farming. Organic waste. Organic farming. Cerrado.

\section{INTRODUÇÃO}

O gergelim (Sesamum indicum L.) é a mais antiga oleaginosa conhecida, tendo como centro de origem a África, onde se concentra a maioria das espécies silvestres do gênero Sesamum (SILVA et al., 2014). A espécie é considerada resistente à seca podendo produzir com um mínimo de pluviosidade bem distribuída, mas a faixa ótima está entre 500 e $650 \mathrm{~mm}$, preferindo solos profundos com textura franca, bem drenados e de boa fertilidade natural (RAMOS et al. 2010; SILVA et al., 2014; ARAUJO et al., 2014).

A cultura do gergelim é cultivada praticamente por pequenos produtores, os quais utilizam tecnologias 
tradicionais de simples manejo para essa cultura e ainda possuem poucos recursos para a aquisição de fertilizantes. Assim, a utilização de esterco bovino e outros resíduos orgânicos é a melhor alternativa para a melhoria das condições físicas e químicas destes solos (PEREIRA et al., 2002; RAMOS et al., 2010).

Nos últimos anos a utilização de adubos orgânicos sólidos e líquidos na produção agrícola teve um crescimento acelerado no Brasil em função dos altos custos dos fertilizantes químicos (OLIVEIRA et al., 2014). Dentre a diversidade de resíduos orgânicos existentes, o esterco bovino se destaca em diversos aspectos possuindo vasta disponibilidade e apresentando percentagens de 30 a $58 \%$ de matéria orgânica (FERREIRA et al., 2012). Estes resíduos atuam sobre a fertilidade do solo aumentando a matéria orgânica, a capacidade de troca de cátions, reduzindo os teores de alumínio trocável. Contribui ainda com o favorecimento de ácidos orgânicos importantes para a solubilidade dos minerais e o incremento na reciclagem e mobilidade de nutrientes, contribuindo para a permeabilidade e infiltração da água (GUIMARÃES, 2008; FOGEL et al., 2013). Além de promover a melhoria de muitos atributos do solo, a aplicação de resíduos orgânicos também aumenta a disponibilidade do fósforo no solo.

A baixa disponibilidade de fósforo $(\mathrm{P})$ para as plantas cultivadas é uma característica predominante dos solos brasileiros em função da sua grande adsorção à fase mineral, predominantemente de baixa reversibilidade, principalmente nos óxidos de $\mathrm{Fe}$ e $\mathrm{Al}$, em especial na região do cerrado, sendo necessária a inclusão desse nutriente por meio da aplicação de fertilizantes fosfatados (SCHONINGER et al., 2013), que associado a adubação orgânica pode aumentar a produção das culturas agrícolas.

A falta de conhecimento sobre a cultura do gergelim em condições de adubação orgânica e fosfatada em clima e solos característicos do Tocantins ainda é um limitador da exploração comercial dessa cultura no
Estado. Diante do exposto o presente trabalho teve como objetivo avaliar a efeito de diferentes níveis de adubação orgânica e fosfatada no cultivo de gergelim (Sesamum indicum L. cv. Trhébua) no Sul do estado do Tocantins.

\section{MATERIAL E MÉTODOS}

O experimento foi conduzido nos meses de fevereiro à julho de 2012, na estação Experimental da Universidade Federal do Tocantins (UFT) - Campus Universitário de Gurupi, localizado no Sul do Estado do Tocantins, nas coordenadas de $11^{\circ} 43,45$ de latitude S e $49^{\circ} 04,07$ de longitude $\mathrm{W}$ e $280 \mathrm{~m}$ de altitude. De acordo com a classificação de Köppen o clima regional é do tipo B1wA'a' úmido com moderada deficiência hídrica. A temperatura média anual é $27^{\circ} \mathrm{C}$ com precipitação média de $1500 \mathrm{~mm}$ anual (FREITAS et al., 2016).

O experimento foi implantado em um LATOSSOLO VERMELHO-AMARELO distrófico de textura média (EMBRAPA, 2013) (Tabela 1), seguindo um delineamento em blocos casualisados (DBC) em esquema fatorial $4 \times 5$, totalizando 20 tratamentos. Sendo o primeiro fator correspondente às doses de adubação fosfatada, nas doses de $0,40,80$ e $120 \mathrm{~kg}$ de $\mathrm{P}_{2} \mathrm{O}_{5}$ ha $^{-1}$ utilizando o fertilizante superfosfato simples. $\mathrm{O}$ segundo fator correspondeu as doses de esterco bovino curtido (EB) cuja caracterização química está apresentada na tabela 2, sendo aplicado nas doses de $0 ; 16,7 ; 33,3 ; 50$ e $66,7 \mathrm{Mg} \mathrm{ha}^{-1}$ de EB. A adubação nitrogenada foi de $50 \mathrm{~kg}$ de $\mathrm{N} \mathrm{ha}^{-1}$ realizada em duas aplicações de $25 \mathrm{~kg}$ de $\mathrm{N} \mathrm{ha}^{-1}$, a primeira 10 dias após o plantio e a segunda 25 dias após a primeira aplicação, no desbaste definitivo, utilizando como fonte a ureia. A adubação potássica foi de $60 \mathrm{~kg}$ de $\mathrm{K}_{2} \mathrm{O} \mathrm{ha}^{-1}$ com uso do cloreto de potássio aplicado na segunda cobertura do nitrogênio seguindo a recomendação de Beltrão e Vieira (2001). A cultivar de gergelim utilizado foi a Trhébua.

Tabela 1 - Caracterização do solo (LATOSSOLO VERMELHO-AMARELO distrófico de textura média*) da área de implantação da cultura do gergelim, Gurupi - TO.

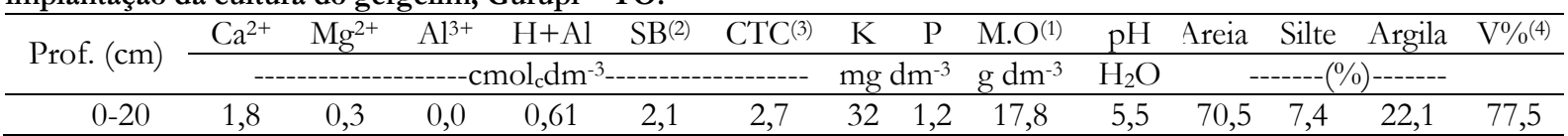

*Segundo o sistema brasileiro de classificação de solos (EMBRAPA, 2013); (1)M.O: Matéria Orgânica; (2)SB: Soma de Bases;

(3) Capacidade de Troca Catiônica em pH 7,0; (4)V\%: Saturação por Bases.

Tabela 2 - Caracterização química do esterco bovino curtido (EB) utilizado como adubação orgânica na cultura do gergelim, Gurupi - TO.

\begin{tabular}{|c|c|c|c|c|c|c|c|c|c|c|c|}
\hline \multirow{3}{*}{ Nutriente } & $\mathrm{N}$ & $\mathrm{P}$ & K & $\mathrm{Na}$ & $\mathrm{Mg}$ & $\mathrm{Ca}$ & $\mathrm{Zn}$ & $\mathrm{Cu}$ & $\mathrm{Fe}$ & $\mathrm{Al}$ & $\mathrm{pH}_{\mathrm{H}_{2} \mathrm{O}}$ \\
\hline & \multicolumn{11}{|c|}{ 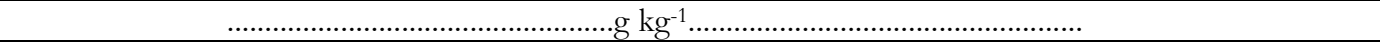 } \\
\hline & 13,7 & 6,7 & 2,11 & 0,32 & - & - & - & - & - & - & 7,8 \\
\hline
\end{tabular}


A aplicação do esterco bovino foi realizada antes do preparo final do solo, sendo distribuído a lanço, em cada faixa segundo as dosagens respectivas de cada tratamento e posteriormente incorporado ao solo com o auxílio da gradagem. A adubação fosfatada foi realizada no sulco de plantio nas quantidades correspondentes a cada tratamento, assim como aplicação da adubação potássica.

O plantio foi realizado no dia 25 de fevereiro de 2012 manualmente, distribuindo as sementes no sulco de plantio após a adubação. A emergência foi observado no dia 02 de março de 2012. Foram realizados dois desbastes, o primeiro aos 10 e o segundo aos 25 dias após o primeiro, a fim de deixar um estande de 20 e 12 plantas por metro linear respectivamente. Densidade esta compatível para a cultivar Trhébua cultivada no assentamento Pontal do Araguaia.

Para avaliação do efeito da adubação orgânica e fosfatada no cultivo de gergelim em condições de solos e clima do Tocantins foram mensurados: Altura de Planta (AP); Altura de Inserção da Primeira Cápsula (AIPC); Quantidade de Cápsulas por Planta (QCP); Quantidade de Sementes por Cápsula (QSC); Peso de Mil Sementes (PMS) e Produtividade por Planta (PP).

$\mathrm{Na}$ data de colheita foram mensurados altura de inserção da $1^{\text {a }}$ cápsula (AIPC) e altura total da planta (AP) por meio de fitas métricas graduadas em $\mathrm{mm}$; e contagem do número de cápsulas por planta (QCP). A colheita foi manual em duas etapas que consistiram no corte e formação das medas, nesta etapa foram retiradas 8 frutos de gergelim e separadas para secagem e deiscência. Posteriormente foi realizado a contagem de sementes por cápsula (QSC). A segunda etapa consistiu na bateção dos feixes de plantas, beneficiamento e limpeza das sementes para a realização da pesagem de mil sementes (PMS), além da determinação da produtividade por planta (PP).

Os dados obtidos foram submetidos à análise de regressão, avaliando a significância dos betas e dos coeficientes de determinação utilizando o programa Statística versão $7.0^{\circledR}$. Os gráficos das regressões foram plotados utilizando o programa estatístico Sigma Plot versão $10.0^{\circledR}$, sendo a escolha dos modelos de regressão baseados na significância dos coeficientes da equação de regressão $(\beta)$ e no coeficiente de determinação $\left(\mathrm{R}^{2}\right)$.

\section{RESULTADOS E DISCUSSÃO}

As variáveis estudadas apresentaram resposta significativa $(p<0,05)$ à aplicação da adubação orgânica e fosfatada, apresentando resposta na sua maioria linear, exceto para quantidade de sementes por cápsula (QSC) e produtividade por planta (PP) que apresentaram resposta quadrática.

Até os 60 dias após a emergência ocorreu suprimento satisfatório de água, ocorrendo neste período precipitação de aproximadamente $228,8 \mathrm{~mm}$, a temperatura média se manteve próxima aos $25{ }^{\circ} \mathrm{C}$, sendo de $27{ }^{\circ} \mathrm{C}$ a faixa máxima desejável para floração/frutificação (PEREIRA et al., 2002), podendo ter favorecido o alongamento do ciclo de cultivo. A umidade relativa manteve-se acima de 60\% (Figura 1).

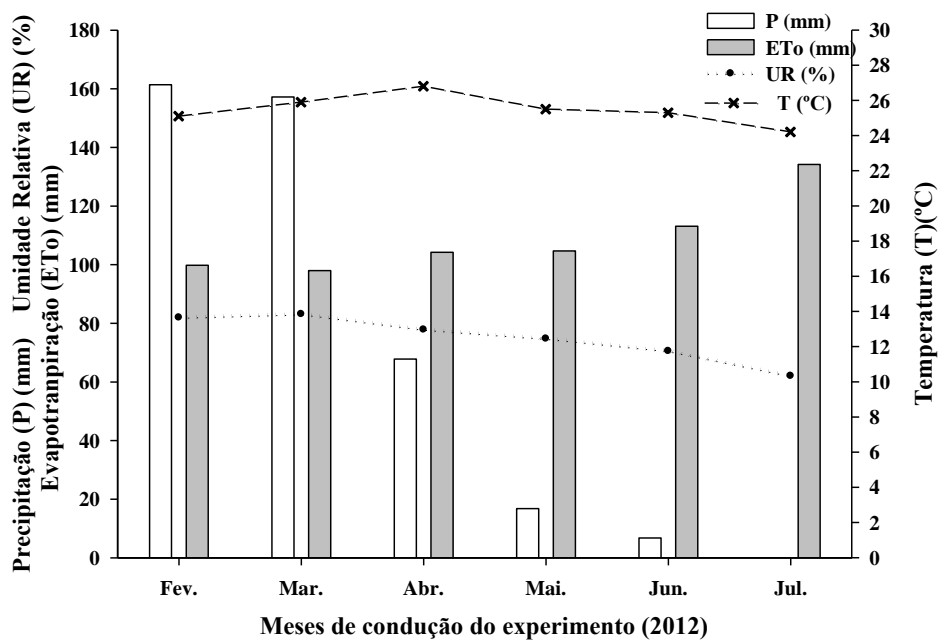

Figura 1 - Dados climáticos mensais do município de Gurupi (TO) durante a condução do experimento no ano de 2012.

No total do ciclo, as chuvas ficaram abaixo do desejável para a cultura do gergelim, mesmo sendo considerada uma espécie resistente à seca, produzindo bem em precipitação de até $300 \mathrm{~mm}$ (desde que cerca de $80 \%$ das chuvas ocorram até o florescimento). A deficiência hídrica na fase de floração/frutificação, leva 
à redução significativa do crescimento da planta e da produção de cápsulas por planta, afetando diretamente a produtividade (PEREIRA et al., 2002). Assim, o fator chuva pode ter sido a principal limitação para a produção da cultura, visto que ocorreu veranico extenso durante o desenvolvimento da cultura. Segundo Araújo et al. (2014), além das condições edafoclimáticas, o

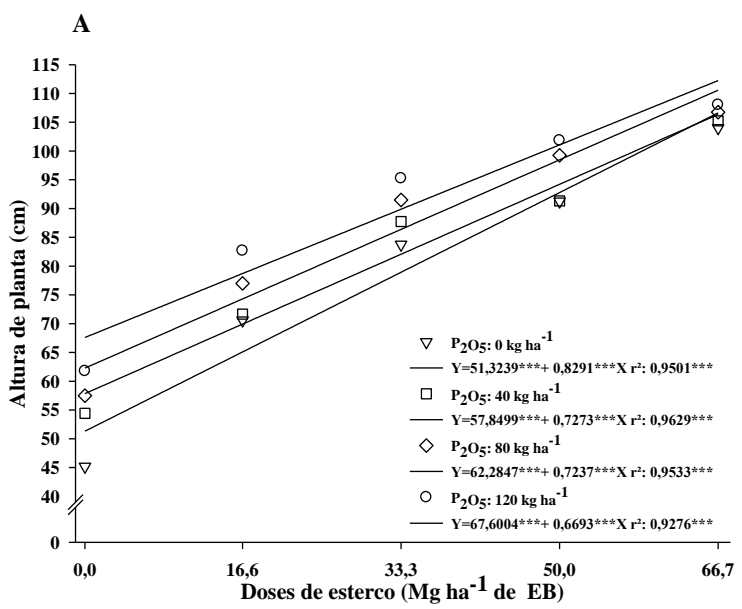

fornecimento de nutrientes às plantas é essencial para que elas apresentem seu máximo potencial produtivo.

A altura de planta (AP) e altura de inserção da primeira cápsula (AIPC) nas plantas apresentaram resposta linear significativa $(p<0,05)$ em função dos níveis crescentes da adubação orgânica com esterco bovino curtido (EB) e da adubação química fosfatada (Figura 2).

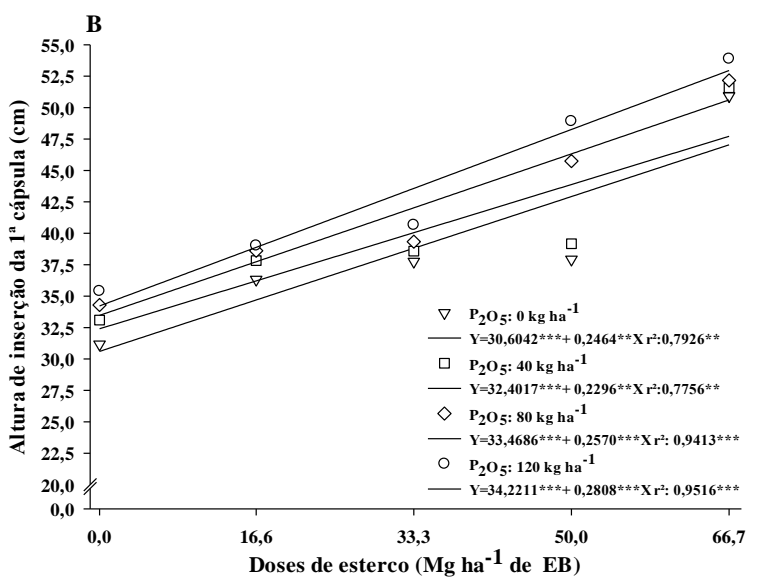

Figura 2 - (A) altura de planta (AP) e (B) altura de inserção da primeira cápsula (AIPC) de Sesamum indicum L. cv. Trhébua em função da adubação orgânica e fosfatada, Gurupi - TO.

A altura de planta apresentou resposta linear significativa $(p<0,01)$ em função da adubação orgânica e fosfatada, mostrando que as plantas podem apresentar potencial resposta a doses de esterco bovino superiores $66,7 \mathrm{Mg} \mathrm{ha} a^{-1}$, em combinação com as doses de fósforo aplicadas.

A aplicação do esterco bovino curtido promoveu um incremento na altura das plantas de aproximadamente $108 \%$ em relação às plantas testemunha, apresentando até $106,63 \mathrm{~cm}$ de altura.

Assim como a altura de planta, a altura de inserção da primeira cápsula apresentou resposta linear significativa $(p<0,05)$ em função da aplicação do esterco bovino, podendo responder a doses superiores de esterco na adubação. A adubação orgânica promoveu um aumento de aproximadamente 54\% na altura de inserção da primeira cápsula, tendo as plantas atingido uma AIPC de 47,03 cm. A adubação química fosfatada promoveu um aumento linear na altura de planta e na altura de inserção da primeira cápsula.

Com a aplicação da adubação fosfatada a altura de planta (AP) aumentou cerca de $17 \mathrm{~cm}$ e a altura de inserção da primeira cápsula (AIPC) aumentou cerca de $3,60 \mathrm{~cm}$ em relação às plantas testemunhas, correspondendo a aproximadamente 32 e $12 \%$ de aumento respectivamente na AP e AIPC em relação às plantas cultivadas sem a adubação fosfatada e orgânica.
A adubação com esterco bovino promoveu um incremento de aproximadamente $58 \%$ na altura de planta e de apenas $6 \%$ na altura de inserção da primeira cápsula em relação à máxima resposta proporcionada pela adubação química fosfatada.

Os resultados obtidos com as combinações da adubação orgânica e fosfatada mostraram uma melhor resposta das plantas de gergelim em altura de planta e altura de inserção da primeira cápsula. Os maiores resultados de AP e AIPC foram obtidos nas maiores combinações de EB e adubação fosfatada, com as plantas atingindo uma altura de $112,25 \mathrm{~cm}$, correspondendo a 66 e 5\% de aumento em relação ao efeito da adubação fosfatada e orgânica (EB), respectivamente. A combinação da adubação orgânica e fosfatada proporcionou às plantas, uma altura de inserção da primeira cápsula de até 49,95 cm, cerca de 46 e $6 \%$ de aumento em relação ao efeito da adubação fosfatada e da adubação orgânica (EB), respectivamente.

Avaliando o crescimento do gergelim adubado com biossólido, Bezerra et al. (2010) verificaram a maior altura de planta, quando comparada as plantas que receberam somente adubação química, corroborando os resultados obtidos neste trabalho. Silva et al. (2010) realizando experimento em casa de vegetação com a cultura do gergelim observaram que a adubação com esterco bovino pode promover um crescimento de 47,6 
cm de altura ou mais com a aplicação de apenas $300 \mathrm{~g}$ de esterco por vaso com capacidade para $7 \mathrm{dm}^{3}$ de solo (85,7 $\left.\mathrm{Mg} \mathrm{ha}^{-1}\right)$. Vasconcelos et al. (2010), estudando a cultura do gergelim afirmam que a AIPC está relacionada com o ciclo de produção da cultivar, pois quanto maior a AIPC mais tardio é o ciclo da cultivar, o que contraria os resultados aqui encontrados, no qual houve variação da AIPC em função dos tratamentos aplicados.

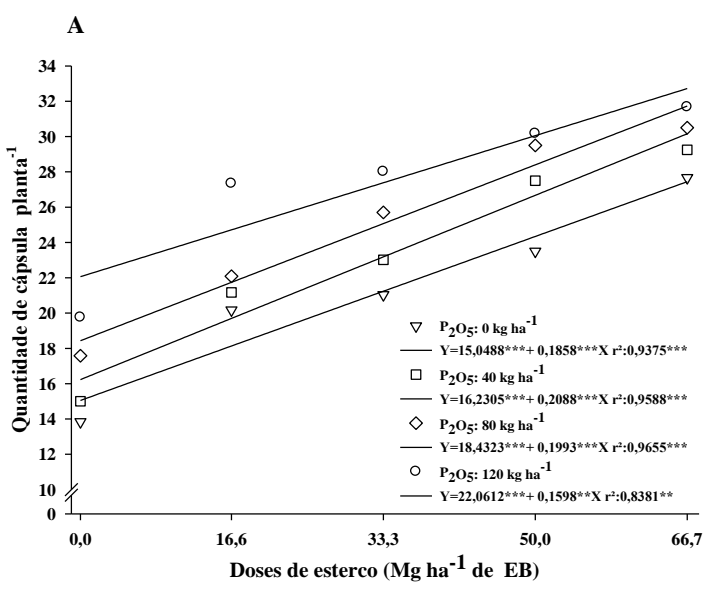

A quantidade de cápsulas por planta (QCP) apresentou resposta linear significativa $(p<0,05)$ em função das doses de esterco bovino (EB) e fosfatada, mostrando potencial resposta à doses superiores de adubação orgânica e fosfatada. Já a quantidade de sementes por cápsula (QSC) apresentou resposta quadrática significativa $(p<0,05)$ em função da adubação orgânica com esterco bovino curtido (EB) e da adubação fosfatada, tendo a combinação apresentado sua máxima eficiência em produção para essa variável (Figura 3).

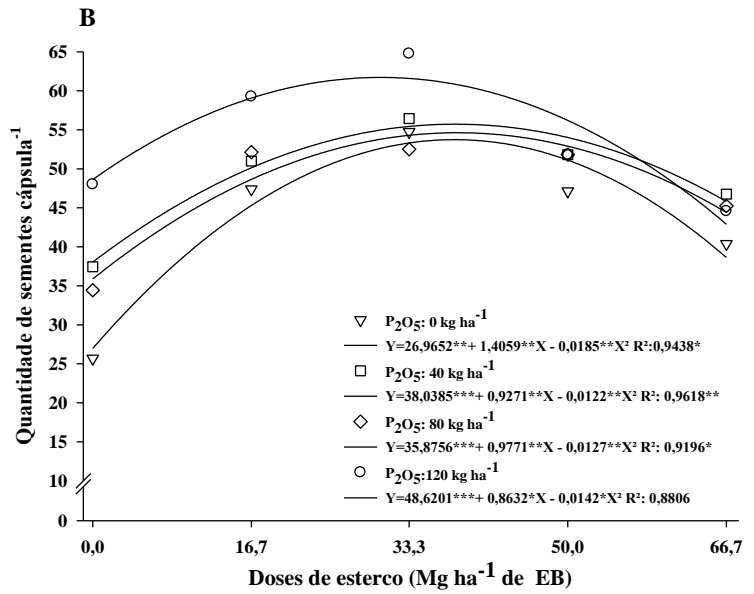

Figura 3 - (A) Quantidade de cápsulas por planta (QCP) e (B) quantidade de sementes por cápsula (QSC) de Sesamum indicum L. cv. Trhébua em função da adubação orgânica e fosfatada, Gurupi-TO.

A aplicação do esterco bovino promoveu um incremento de aproximadamente $82 \%$ na QCP em relação às plantas testemunhas (12 cápsulas). A adubação fosfatada promoveu um aumento linear na quantidade de cápsulas por planta, tendo as plantas apresentado aproximadamente $47 \%$ de cápsulas a mais que as testemunhas. A quantidade de sementes por cápsula (QSC) apresentou máxima resposta nas doses de $37,99,37,99,38,74$ e $30,39 \mathrm{Mg}$ de $\mathrm{EB} \mathrm{ha}^{-1}$, para as doses de 0, 40, 80 e $120 \mathrm{~kg}$ de $\mathrm{P}_{2} \mathrm{O}_{5} \mathrm{ha}^{-1}$, respectivamente.

$\mathrm{A}$ adubação orgânica apresentou sua máxima resposta na dose de $37,99 \mathrm{Mg}$ de $\mathrm{EB} \mathrm{ha}{ }^{-1}$, tendo as plantas apresentado nessa dose 53,68 sementes por cápsula. A adubação fosfatada promoveu um incremento linear na quantidade de sementes por cápsula aumentando em até 21 sementes na maior dose da adubação fosfatada, apresentando um incremento de aproximadamente $81 \%$ em relação à dose $0 \mathrm{~kg}$ de $\mathrm{P}_{2} \mathrm{O}_{5}$ ha $^{-1}$. A aplicação do esterco bovino promoveu um incremento de aproximadamente $26 \%$ na quantidade de cápsula por planta e de $11 \%$ na quantidade de sementes por cápsula em relação à máxima eficiência da adubação fosfatada.

Os resultados obtidos com as combinações da adubação orgânica e fosfatada mostraram que a quantidade de cápsula por planta sofreu influência significativa, aumentando cerca de $117 \%$, atingindo 32,72 cápsulas por planta e apresentando ainda potencial reposta às doses superiores de adubações.

Já a quantidade de sementes por cápsula (QSC) apresentou sua máxima resposta na combinação de 30 $\mathrm{Mg}$ de $\mathrm{EB} \mathrm{ha}{ }^{-1}$ com $120 \mathrm{~kg}$ de $\mathrm{P}_{2} \mathrm{O}_{5} \mathrm{ha}^{-1}$, promovendo um incremento de aproximadamente $130 \%$ em relação às plantas testemunhas, de aproximadamente $27 \% \mathrm{em}$ relação à aplicação de $\mathrm{P}_{2} \mathrm{O}_{5}$ e de apenas 15\% em relação à aplicação somente do EB.

A combinação da adubação orgânica e fosfatada na sua máxima eficiência proporcionou um aumento de 15 e $27 \%$ na quantidade de cápsula por planta (QCP) em relação à adubação orgânica e fosfatada respectivamente. Já a quantidade de cápsula sofreu um aumento de 48 e $21 \%$ em relação à adubação fosfatada e orgânica com o EB respectivamente.

Segundo Vasconcelos et al. (2010) a quantidade de cápsulas está diretamente relacionada com a produtividade da cultura, sendo que com maior quantidade de cápsulas, maior será a quantidade de sementes, consequentemente maior a produtividade. Corroborando com os resultados Pereira et al. (2002) 
que verificaram o aumento da QCP em função das aplicações de EB.

Segundo Ramos et al. (2010) ocorrem diferenças estatísticas significativas na QCP entre doses de esterco no cultivo do gergelim, apresentando resposta quadrática em função do aumento das doses de EB. Esta resposta pode ser atribuída ao fato de que estes pesquisadores utilizaram doses de até $1000 \mathrm{~g}$ de esterco bovino (EB) por vaso com capacidade de $7 \mathrm{dm}^{-3}$ de solo (571,4 Mg ha $\left.\mathrm{Mg}^{-1}\right)$. Discordando com os resultados encontrados, Perin et al. (2010) afirmam que tanto a adubação química quanto a adubação orgânica não exercem influência sobre a QCP.

Pouco se tem estudado sobre a QSC, pois a mesma varia entre cultivares, sendo assim para esta cultivar a adubação orgânica e fosfatada promoveu aumento da quantidade de sementes. Magalhães et al. (2010) estudando o efeito da adubação orgânica verificaram aumento da QSC em função das doses de $\mathrm{EB}$, com resposta linear, podendo ser explicada pela subdosagem de EB, sendo que utilizou dose máxima de $40 \mathrm{Mg}$ de $\mathrm{EB} \mathrm{ha} \mathrm{a}^{-1}$. O autor concluiu que o mesmo responderia a doses superiores, o que ficou provado neste experimento.

O peso de mil sementes (PMS) apresentou resposta linear significativa $(p<0,05)$, já a produtividade por planta (PP) apresentou resposta quadrática significativa $(p<0,05)$ em função da adubação orgânica com o EB e da adubação fosfatada (Figura 4).
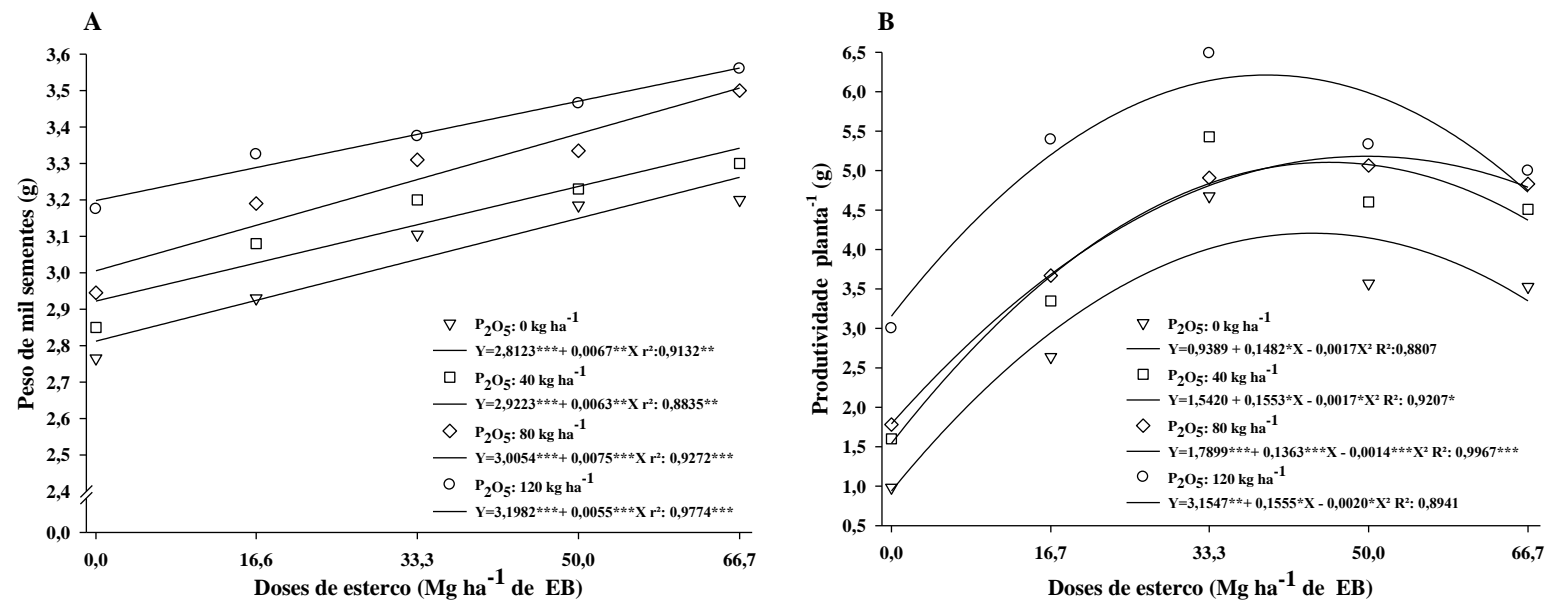

Figura 4 - (A) peso de mil sementes (PMS) e (B) produtividade por planta (PP) de Sesamum indicum L. cv. Trhébua em função da adubação orgânica e fosfatada, Gurupi-TO.

O peso de mil sementes (PMS) aumentou em função das adubações realizada, mostrando ainda potencial resposta a doses superiores da adubação orgânica e fosfatada. A adubação orgânica proporcionou um incremento de $16 \%$ no PMS na sua máxima dose quando comparada a dose $0 \mathrm{Mg}$ de $\mathrm{EB} \mathrm{ha}{ }^{-1}$, tendo as plantas atingido o peso de mil sementes (PMS) de 3,26 $\mathrm{g}$ em função da maior dose de esterco bovino (EB). A adubação fosfatada promoveu um aumento de 14\% no PMS comparando a produção das plantas testemunha a máxima dose da adubação fosfatada aplicada. Com a adubação fosfatada as plantas apresentaram peso de mil sementes de 3,20 g na máxima dose aplicada.

As produtividades máximas foram obtidas nas doses 43,58, 45,67, 48,67 e 38,87 $\mathrm{Mg} \mathrm{ha}^{-1}$ de EB nas doses de $0,40,80$ e $120 \mathrm{~kg} \mathrm{ha}^{-1}$ de $\mathrm{P}_{2} \mathrm{O}_{5}$ respectivamente. A produtividade por planta (PP) sofreu influência significativa da adubação orgânica, tendo apresentado na máxima dose eficiente de esterco bovino $(43,58 \mathrm{Mg}$ de
EB ha ${ }^{-1}$ ) um incremento de $343 \%$ em relação às plantas testemunhas, chegando a PP de 4,16 g. A adubação fosfatada na sua máxima dose aplicada $\left(120 \mathrm{~kg}\right.$ de $\mathrm{P}_{2} \mathrm{O}_{5}$ $\left.\mathrm{ha}^{-1}\right)$ promoveu um incremento de $235 \%$ na produtividade por planta, atingindo 3,15 $\mathrm{g}_{\text { }}$ lanta $^{-1}$.

A combinação da adubação orgânica e fosfatada apresentou as maiores produtividades da cultura do gergelim. A maior produtividade por planta (PP) foi obtida quando se utilizou a dose de $120 \mathrm{~kg}$ de $\mathrm{P}_{2} \mathrm{O}_{5} \mathrm{ha}^{-1}$ com dose de $38,87 \mathrm{Mg}$ de $\mathrm{EB}$ ha $^{-1}$. Essa combinação proporcionou um incremento de $557 \%$ em relação às plantas testemunhas, enquanto foi superior em $96 \%$ em relação à máxima resposta da adubação fosfatada e de $49 \%$ em relação à máxima dose eficiente de esterco bovino $\left(43,58 \mathrm{Mg}\right.$ de $\left.\mathrm{EB} \mathrm{ha} \mathrm{ha}^{-1}\right)$, tendo atingido uma produtividade de $6,18 \mathrm{~g} \mathrm{planta}^{-1}$.

Em estudo realizado com a cultura do gergelim cultivado em casa de vegetação, utilizando adubação mineral e orgânica Nascimento et al. (2006) e Bezerra et 
al. (2010) verificaram efeito equivalente da adubação orgânica em relação à adubação mineral, ambos apresentando rendimento de grãos semelhantes. Já Magalhães et al. (2010) estudando o efeito da adubação orgânica na produção de gergelim em casa de vegetação, não observaram diferença entre as doses de esterco bovino aplicadas. Estes resultados discordam com os resultados apresentados nesta pesquisa, onde as plantas que receberam apenas adubação orgânica com o EB apresentaram diferenças nos resultado entre as doses aplicadas de EB, apresentando peso dos grãos superior à aplicação somente da adubação fosfatada.

Lima et al. (2013) estudando o efeito de biofertilizante bovino na produtividade do gergelim, verificou que o mesmo proporciona um aumento na produtividade por planta (PP), tendo as plantas melhor resultado na aplicação do biofertilizante. Segundo Araújo (2005), isso ocorre por que a fração solúvel do esterco tem por característica manter o fósforo e outros nutrientes essenciais de forma disponível e absorvível pelas plantas, o que proporciona maior desenvolvimento e produção à cultura.

\section{CONCLUSÕES}

A adubação orgânica e fosfatada aumenta a produção do gergelim em solo característico do cerrado.

A adubação orgânica é como uma alternativa eficiente, de alta disponibilidade e barata de adubação para a cultura do gergelim nas condições edafoclimáticas avaliadas.

A adubação fosfatada é imprescindível para a produção do gergelim no cerrado, porém a adubação com uso de esterco promove produção cerca de 32\% superior a adubação fosfatada, sendo indicada para a melhoria da fertilidade do solo e aumento da produção da cultura.

\section{AGRADECIMENTOS}

"O presente trabalho foi realizado com o apoio do Conselho Nacional de Desenvolvimento Científico e Tecnológico - CNPq - Brasil”.

\section{REFERÊNCIAS BIBLIOGRÁFICAS}

ARAÚJO, E. N. Rendimento do pimentão (Capsicum annum L.) adubado com esterco bovino e biofertilizante. 2005.98 p. Dissertação (Mestrado em Agronomia). Universidade Federal da Paraíba, Areia-PB, 2005.

ARAÚJO, F. S.; BORGES, S. R. S.; SILVA, G. Z.; ARAÚJO, L. H. B.; TORRES, E. J. M. Doses de fósforo no crescimento inicial do gergelim cultivado em solução nutritiva. Revista Tecnologia \& Ciência Agropecuária, v.8, n.2, p. 41-47, 2014.
BELTRÃO, N. E. M.; VIEIRA, D. J. O agronegócio do gergelim no Brasil. Brasília. Embrapa Informação tecnológica, 348 p. 2001.

BEZERRA, S. A.; NETO, J. D.; AZEVEDO, C. A. V.; SILVA, M. B. R.; SILVA, M. M. Produção do gergelim cultivado sob condições de estresse hídrico e diferentes doses de adubação. Engenharia Ambiental, v.7, n.3, p. 156 $-165,2010$.

EMBRAPA - Empresa Brasileira de Pesquisa Agropecuária. Sistema brasileiro de classificação de solos. Centro Nacional de Pesquisa de Solos, 3. ed. Brasília: Embrapa Solos, 2013. 353 p.

FERREIRA, T. C.; SILVA, K. E.; SOUZA, J. T. A.; OLIVEIRA, S. J. C. Produção de gergelim Sesamum indicum L. orgânico no agreste paraibano. Revista de Biologia e Farmácia, v.7, n.2, p.112-118, 2012.

FOGEL, G. F.; MARTINKOSKI, L.; MOKOCHINSKI, F. M.; GUILHERMETTI, P. G. C.; MOREIRA, V. S. Efeitos da adubação com dejetos suínos, cama de aves e fosfato natural na recuperação de pastagens degradadas. Revista Verde de Agroecologia e Desenvolvimento Sustentável, v.8, n.5, p. 66 - 71, 2013.

FREITAS, G. A.; BENDITO, B. P. C.; SANTOS, A. C. M.; SOUSA, P. A. Diagnóstico ambiental de áreas de pastagens degradadas no município de Gurupi-TO. Biota Amazônia, v. 6, n. 1, p. 10 - 15, 2016.

GUIMARÃeS, A. S. Crescimento inicial do Pinbão Manso (Jatrophas curcas L.) em função de fontes e quantidades de fertilizante. 2008. 92 p. Tese (Doutorado em Ecologia Vegetal e Meio Ambiente) - Centro de Ciências Agrárias - Universidade Federal da Paraíba, Areia - PB, 2008.

LIMA, F. A.; SOUSA, G. G.; VIANA, T. V. A.; PINHEIRO NETO, L. G.; AZEVEDO, B. M.; CARVALHO, C. M. Irrigação da cultura do gergelim em solo com biofertilizante bovino. Revista Brasileira de Agricultura Irrigada, v.7, n.2, p.102 - 111, 2013.

MAGALHÃES, I. D.; COSTA, F. E.; ALVES, G. M. R.; ALMEIDA, A. E. S.; SILVA, S. D.; SOARES, C. S. Produção de gergelim orgânico sob condições semiáridas. In: IV Congresso Brasileiro de Mamona \& I Simpósio Internacional de Oleaginosas Energéticas, João Pessoa-PB, 2010. Anais... Campina grande: Embrapa Algodão, 2010 p. 749-754.

NASCIMENTO, J. J. V. R.; SOUSA, J. S. C.; FERREIRA, D. J. L.; MENDES, L. B.; BEZERRA, S. A.; AZEVEDO, C. A. V. Rendimento de Grãos por Capulho do Gergelim Cultivar CNPA G4, Sob Déficit 
Hídrico e Adubação com duas Fontes de Nitrogênio. Revista Educação Agrícola superior, v.21, n.2, p.63-64, 2006.

OLIVEIRA, A. P.; SILVA, O. P. R.; BANDEIRA, N. V. S.; SILVA, D. F.; SILVA, J. A.; PINHEIRO, S. M. $G$. Rendimento de maxixe em solo arenoso em função de doses de esterco bovino e biofertilizante. Revista Brasileira de Engenharia Agrícola e Ambiental, v.18, n.11, p.1130-1135, 2014.

PEREIRA, J. R.; BELTRÃO, N. E. M.; ARRIEL, N. H. C.; SILVA, E. S. B. Adubação Orgânica do Gergelim, no Seridó Paraibano. Revista Brasileira de Oleaginosas e Fibrosas, v.6, n.3, 599-608, 2002.

PERIN, A.; CRUVINEL, D. J.; SILVA, J. W. Desempenho do gergelim em função da adubação NPK e do nível de fertilidade do solo. Acta Scientiarum Agronomy, v.32, n.1, p.93-98, 2010.

RAMOS, J. P. C.; JÚNIOR, J. N. S. M.; SOUZA, F. F.; FERNANDES, J. D.; LIMA, V. I. Comportamento do número de frutos do gergelim (Sesamum indicum) sob diferentes quantidades de esterco bovino. In: IV Congresso Brasileiro de Mamona \& I Simpósio Internacional de Oleaginosas Energéticas, João PessoaPB, 2010. Anais... Campina grande: Embrapa Algodão, 2010, p. 509-513.

SCHONINGER, E. L.; GATIBONI, L. C.; ERNANI, P. R. Fertilização com fosfato natural e cinética de absorção de fósforo de soja e plantas de cobertura do cerrado. Semina: Ciências Agrárias, v.34, n.1, p.95-106, 2013.

SILVA, J. R. P.; FERREIRA, T. C.; SOUZA, J. T. A.; PEREIRA, G. L.; DANTAS, J. P. Influência de doses crescentes de esterco bovino no número de folhas e ramos do gergelim (Sesamum indicum). In: IV Congresso Brasileiro de Mamona \& I Simpósio Internacional de Oleaginosas Energéticas, João Pessoa-PB, 2010. Anais... Campina grande: Embrapa Algodão, 2010, p. 721-725.

SILVA, J. C. A.; FERNANDES, P. D.; BEZERRA, J. R. C.; ARRIEL, N. H. C.; CARDOSO, G. D. Crescimento e produção de genótipos de gergelim em função de lâminas de irrigação. Revista Brasileira de Engenharia Agricola e Ambiental, v.18, n.4, p. 408-416, 2014.

VASCONCELOS, R. A.; GONDIM, T. M. S.; ARRIEL, N. H. C. Características vegetativas e reprodutivas de genótipos de gergelim no cariri cearense. In: IV Congresso Brasileiro de Mamona \& I Simpósio Internacional de Oleaginosas Energéticas, João Pessoa-PB, 2010. Anais... Campina grande: Embrapa Algodão, 2010, p. 1599-1605. 